\title{
Decoupled fermentation and respiration in permeable sediments - a dihydrogen conundrum
}

\author{
PhilipP A. NAUER ${ }^{1 *}$, AdAM J. KeSSLER ${ }^{1}$, TeSS \\ HUTCHINSON $^{1}$, KARL M. ATTARD $^{2}$, RONNIE N. GLUD ${ }^{2}$, \\ Chris GREENING ${ }^{1}$, PERRAN L. M. COOK ${ }^{1}$ \\ ${ }^{1}$ Monash University, Clayton VIC 3800, Australia; \\ ${ }^{2}$ University of Southern Denmark, 5230 Odense, Denmark; \\ *correspondence: philipp.nauer@monash.edu
}

Diydrogen $\left(\mathrm{H}_{2}\right)$ is an important and widely used intermediate in anaerobic microbial processes. Its role as both electron source and sink make it a highly valuable currency in the microbial world, and concentrations are generally tightly controlled by thermodynamic limits of consumption and production processes. However, recent studies have found substantial hydrogen accumulation in permeable marine sediments under anoxic conditions [1,2]. Initially attributed to algal dark fermentation [1], it could later be demonstated that fermentation is of bacterial origin, and the dominating respiratory process in anoxic permeable marine sediments, sulfate reduction, was uncoupled from fermentation [2]. Here we investigate the prerequisites, extent and prevalence of such $\mathrm{H}_{2}$ accumulation in- and ex situ. Slurry experiments with sandy sediments from diverse sites confirmed previous results of transient $\mathrm{H}_{2}$ accumulation when slurries were constantly shaken; $\mathrm{H}_{2}$ later stabilized around 2-6 $\mathrm{nM}$, typical for a coupled fermentation - sulfate-reduction steady-state. However, in still slurries $\mathrm{H}_{2}$ remained close to this level throughout. Flowthrough reactors (FTRs) showed similar behavior to shaken slurries, regardless of induced physical disturbance of the sand column. Advective flow is thus a necessity for uncoupling, while physical disturbance is not. The role of oxygen remains the subject of ongoing investigations. Initial FTR results show no induction of $\mathrm{H}_{2}$ accumulation by a $24 \mathrm{~h}$ oxic phase after prolonged anoxia; yet, reactors with inhibited sulfate reduction confirmed ongoing fermentation and high $\mathrm{H}_{2}$ levels, with only a brief collapse of $\mathrm{H}_{2}$ production during the oxic phase. Sulfate reducers thus appear to survive and promptly resume activity after an oxic phase. Contrary to laboratory experiments we could not detect $\mathrm{H}_{2}$ accumulation in situ, neither in sediment porewater nor the water column, during several field campaigns covering various sites. We hypothesize that field conditions seldom align for $\mathrm{H}_{2}$ to accumulate, either due to frequent oxic-anoxic shifts replenishing more favourable electron acceptors, or due to prolonged anoxia allowing sulfate reducers to become firmly established.

[1] Bourke et al. (2016) Nat Geosci 10 30-35. [2] Kessler et al. (2019) Nat Microbiol 4 1014-1023. 